\title{
Lower incidence of contrast-induced nephropathy in patients undergoing fluorescent angiography
}

\author{
Ji Hwan Lee ${ }^{1}$, Byunghoon Chung ${ }^{2}$, Sung Chul Lee ${ }^{1}$, Sung Soo Kim', Hyoung Jun Koh ${ }^{1}$ \\ and Christopher Seungkyu Lee
}

\begin{abstract}
Background: To evaluate the incidence and risk factors of contrast-induced nephropathy (CIN) in patients undergoing fluorescein angiography (FA).

Methods: One hundred sixty patients who underwent FA as a part of ophthalmic examination and had serum creatinine (SCr) results within 24 h before FA and within 72 h after FA between 2005 and 2013 at a tertiary medical center were included. According to baseline $\mathrm{SCr}$ levels, the subjects were divided into low-risk group $(<1.5 \mathrm{mg} / \mathrm{dL})$, intermediate-risk group (1.5-2.0 mg/dL), and high-risk group ( $>2.0 \mathrm{mg} / \mathrm{dL})$ for CIN development. The CIN incidence, and changes in renal function defined by SCr levels and estimated glomerular filtration rate (eGFR) were evaluated. Demographics and comorbidities were analyzed to investigate an association with CIN development.

Results: Of 160 patients, 91 were males (56.9\%). The mean age was $52.46 \pm 17.81$ years. Two (1.3\%) patients developed CIN after FA, whose SCr levels returned to normal within 10 days without hemodialysis. Overall, there were no changes before and after FA in SCr level $(1.52 \pm 1.31 \mathrm{mg} / \mathrm{dL}$ vs. $1.51 \pm 1.28 \mathrm{mg} / \mathrm{dL}$, respectively; $p=0.93)$ and eGFR $\left(67.02 \pm 36.62 \mathrm{~mL} / \mathrm{min} / 1.73 \mathrm{~m}^{2}\right.$ vs. $66.41 \pm 36.54 \mathrm{~mL} / \mathrm{min} / 1.73 \mathrm{~m}^{2}$, respectively; $\left.p=0.54\right)$. SCr level and eGFR remained unchanged after FA in low-risk and intermediate-risk groups. In high-risk group, eGFR remined unchanged, but $\mathrm{SCr}$ level decreased after FA (from $3.64 \pm 1.59 \mathrm{mg} / \mathrm{dL}$ to $3.53 \pm 1.60 \mathrm{mg} / \mathrm{dL} ; p=0.04$ ). Basline $\mathrm{SCr}$ and cormorbidities did not predict CIN development.
\end{abstract}

Conclusions: Acute renal function deterioration was not evident in patients undergoing FA regardless of baseline renal function and comorbidities.

Keywords: Acute kidney injury, Contrast media, Fluorescein angiography

\section{Background}

Fundus fluorescein angiography (FA) is a crucial imaging tool in the diagnosis and management of various retinal diseases including diabetic retinopathy, age-related macular degeneration, and uveitis. Adverse reactions are usually mild and transient, but may include serious reactions such as anaphylaxis, seizures, and death [1-6]. Sodium fluorescein $\left(\mathrm{C}_{20} \mathrm{H}_{12} \mathrm{O}_{5} \mathrm{Na}\right.$, molecular weight $\left.376.27 \mathrm{~g} / \mathrm{mol}\right)$, a

\footnotetext{
* Correspondence: sklee219@yuhs.ac

${ }^{1}$ The Institute of Vision Research, Department of Ophthalmology, Yonsei

University College of Medicine, Severance Hospital, Yonsei-ro 50-1

Sodaemun-gu, Seoul 03722, Republic of Korea

Full list of author information is available at the end of the article
}

noniodinated contrast media used in FA is largely eliminated by the kidneys within $24 \mathrm{~h}$, [7] so patients with renal insufficiency may be at increased risk of nephrotoxicity after FA. Common practice may dictate the avoidance of FA in patients with renal insufficiency, but patients who require FA imaging for conditions such as diabetic retinopathy often have concurrent kidney problems $[8,9]$.

Contrast-induced nephropathy (CIN) is a form of acute kidney injury defined by acute elevation of serum creatinine (SCr), generally within $72 \mathrm{~h}$ after the injection of contrast medium. CIN has been known to increase the cost of medical care, duration of hospital stay, and risk of serious long-term adverse events such as permanent 
renal impairment, myocardial infarction, pulmonary edema, stroke, and death [10]. CIN has received increasing attention in patients undergoing percutaneous coronary angiography or contrast-enhanced computed tomography (CT) scans $[10,11]$. Known risk factors for CIN include older age, diabetes mellitus (DM), pre-existing renal failure, heart failure, higher volumes of injected contrast media, dehydration, and concurrent nephrotoxic drugs [11]. However, CIN in the ophthalmological field has not been investigated, yet; PubMed search (keywords: contrastinduced nephropathy and fluorescein angiography) showed no report on CIN associated with FA. We conducted a retrospective study to investigate whether FA is associated with the deterioration of acute renal function and determine the CIN occurrece rate and associated risk factors.

\section{Methods}

Medical records for all patients seen at the Department of Ophthalmology, Severance Hospital, College of Medicine, Yonsei University between November 2005 and October 2013 were screened retrospectively. This study was approved by the Institutional Review Board of Severance hospital (IRB No.4-2014-0799) and was conducted in accordance with the Declaration of Helsinki.

Patients were included if they had: (a) undergone FA between November 1, 2005 and October 31, 2013 (b) baseline SCr results within $24 \mathrm{~h}$ before FA (c) $\mathrm{SCr}$ results within $72 \mathrm{~h}$ after FA. Exclusion criteria included pre-existing medical conditions requiring renal dialysis and having undergone concurrent CT scans or percutaneous angiography using contrast media within two weeks before FA [12]. If there were two or more post-FA SCr levels available within $72 \mathrm{~h}$ after $\mathrm{FA}$, the highest $\mathrm{SCr}$ level was selected.

Predisposing medical/ophthalmologic conditions that are known to be risk factors for CIN were identified using International Classification of Diseases, Tenth Edition, Clinical Modification (ICD-10), which included diabetic nephropathy (DMN), congestive heart failure (HF), and chronic kidney disease (CKD). The diagnosis of CKD was confirmed using conventional criteria (estimated glomerular filtration rate (eGFR) $<60 \mathrm{~mL} / \mathrm{min} /$ $1.72 \mathrm{~m}^{2}$ ) [11, 13-15]. eGFR was calculated using the Modification of Diet in Renal Disease formula and included serum albumin and blood urea nitrogen levels.

Patients were stratified according to baseline $\mathrm{SCr}$ level as follows: low-risk group $(\mathrm{SCr}<1.5 \mathrm{mg} / \mathrm{dL})$, intermediaterisk group ( $\mathrm{SCr} 1.5-2.0 \mathrm{mg} / \mathrm{dL}$ ) and high-risk group $(\mathrm{SCr}>2.0 \mathrm{mg} / \mathrm{dL})$ [16-18].

CIN was defined as a rise in SCr level of $0.5 \mathrm{mg} / \mathrm{dL}$ or greater or as a $25 \%$ increase over baseline level within $72 \mathrm{~h}$ after FA $[19,20]$. In the present study, a rise in $\mathrm{SCr}$ level of $0.5 \mathrm{mg} / \mathrm{dL}$ was chosen as a threshold value over $0.3 \mathrm{mg} / \mathrm{dL}$, which was recently proposed by the Acute
Kidney Injury Network, because higher value is potentially more specific, less likely to yield false-positive results from cumulative biologic and assay variability, and more commonly used as a definition of CIN in current medical practice $[17,19,21,22]$.

All patients received $500 \mathrm{mg}$ of sodium fluorescein (Novartis, Basel, Switzerland) intravenously through an antecubital vein in 5-8 s. Statistical analyses were performed using R software (version 2.15, R Foundation for Statistical Computing, Vienna, Austria). A paired student's $t$ test and Wilcoxon signed rank test were used to compare $\mathrm{SCr}$ between various groups; all $p$ values of $<0.05$ were considered statistically significant.

\section{Results}

A total of 160 patients (91 male, 69 female) were lincluded. The mean age was $52.46 \pm 17.81$ years. The demographic information and clinical findings are presented in Table 1. Post-FA SCr and eGFR were obtained within $24 \mathrm{~h}$ after FA in 96 patients (60.0\%), between 24 and $48 \mathrm{~h}$ in 42 patients (26.3\%), and between 48 and $72 \mathrm{~h}$ in 22 patients (13.7\%). Baseline SCr level was $1.52 \pm 1.31 \mathrm{mg} / \mathrm{dL}$, and baseline eGFR was $67.02 \pm 36.62 \mathrm{~mL} / \mathrm{min} / 1.73 \mathrm{~m}^{2}$. There were no changes in SCr level and eGFR after FA.

When patients were grouped according to their baseline $\mathrm{SCr}$ levels, there were no changes in $\mathrm{SCr}$ level and eGRF after FA in low-risk group and intermediate-risk group. In high-risk group, SCr level decreased after FA, while there was no change in eGFR (Table 1). SCr levels and eGFR remained unchanged after FA when they were analyzed according to coexisting medical/ophthalmologic conditions that are known risk factors of CIN (Table 2). SCr levels and eGFR did not change after FA regardless of whether patients were inpatients or outpatients (Table 3 ).

Of 160 patients, 2 (1.3\%) patients developed CIN, 1 in the low-risk group and 1 in the intermediate-risk group (Table 4). Patient number 1 was a 53-year-old male with underlying hypertension. He was admitted to the ophthalmology department due to bilateral acute syphilitic posterior placoid chorioretinitis. His SCr level increased from $0.84 \mathrm{mg} / \mathrm{dL}$ to $2.08 \mathrm{mg} / \mathrm{dL} 24 \mathrm{~h}$ after FA; however, $\mathrm{SCr}$ level decreased rapidly and was normalized to baseline level $(0.81 \mathrm{mg} / \mathrm{dL})$ within 3 days without treatment. Patient number 2 was a 62-year-old diabetic male. $\mathrm{He}$ was admitted due to sphenoethmoidal aspergillosis and was evaluated in ophthalmological department for decreased visual acuity. His SCr level increased by $0.8 \mathrm{mg} / \mathrm{dL}$ after FA $(1.5 \mathrm{mg} / \mathrm{dL}$ to $2.3 \mathrm{mg} / \mathrm{dL})$ within 72 h. Nephrologist suspected amphotericin-related nephropathy and changed systemic medication from amphotericin B to voriconazole. His $\mathrm{SCr}$ level decreased to baseline level $(1.7 \mathrm{mg} / \mathrm{dL})$ within 10 days. 
Table 1 Demographic Information, SCr Levels, and eGFR for Patients with Presumed Risk of Developing Acute Kidney Injury

\begin{tabular}{lllll}
\hline Group & Total & Low risk & Intermediate risk & High risk \\
\hline Number & 160 & 113 & 15 & 32 \\
Age & $52.46 \pm 17.81$ & $51.76 \pm 18.84$ & $54.87 \pm 14.28$ & $53.78 \pm 15.64$ \\
Sex $(\mathrm{M} / \mathrm{F})$ & $91 / 69$ & $55 / 58$ & $7 / 8$ & $29 / 3$ \\
Pre-SCr $(\mathrm{mg} / \mathrm{dL})$ & $1.52 \pm 1.31$ & $0.90 \pm 0.27$ & $1.60 \pm 0.11$ & $3.64 \pm 1.59$ \\
Post-SCr $(\mathrm{mg} / \mathrm{dL})$ & $1.51 \pm 1.28$ & $0.93 \pm 0.32$ & $1.63 \pm 0.26$ & $3.53 \pm 1.60$ \\
p value & 0.93 & 0.13 & 0.65 & $0.04^{*}$ \\
Pre-eGFR $\left(\mathrm{mL} / \mathrm{min} / 1.73 \mathrm{~m}^{2}\right)$ & $67.02 \pm 36.62$ & $84.47 \pm 29.71$ & $41.81 \pm 6.77$ & $21.56 \pm 8.81$ \\
Post-eGFR $\left(\mathrm{mL} / \mathrm{min} / 1.73 \mathrm{~m}^{2}\right)$ & $66.41 \pm 36.54$ & $83.23 \pm 30.69$ & $41.36 \pm 6.76$ & $22.93 \pm 10.47$ \\
$p$ value & 0.54 & 0.37 & 0.81 & 0.08 \\
\hline
\end{tabular}

Values are presented as mean \pm SD (standard deviation)

${ }^{*} p$ value $<0.05$

\section{Discussion}

There were no significant changes in $\mathrm{SCr}$ levels and eGFR after FA in patients with various baseline $\mathrm{SCr}$ levels. In the high-risk group, $\mathrm{SCr}$ levels actually decreased following FA, but this change is clinically insignificant, as a reduction in SCr after FA may not indicate improvement in renal function. Female gender has been identified as an independent risk factor for CIN [23]. The relatively lower portion of female patients in high-risk group than intermediate and low-risk groups (9.4\% Vs $46.7 \%$ and 48.7\%) may have affected results in the high-risk group after FA. We analyzed eGFR in addition to $\mathrm{SCr}$, as $\mathrm{SCr}$ values can vary with age, muscle mass, and sex. Both $\mathrm{SCr}$ and eGFR remained unchanged after FA regardless of baseline $\mathrm{SCr}$ levels, coexisting comorbidities, and inpatient/outpatient status.

CIN has been investigated mainly in the field of cardiology and radiology. CIN occurs in $5.2-33 \%$ of patients undergoing cardiac catheterization [24] and $4-12 \%$ of patients undergoing a contrast-enhanced CT scan [20, 25-28]. The rate of $1.3 \%$ found in the present study appeared to be significantly lower compared to CIN associated with cardiac catheterization and contrast CT scans. Intra-arterial administration of contrast media, higher dosage, and the invasive

Table 2 Changes in Serum Creatinine and eGFR According to Coexisting Conditions

\begin{tabular}{|c|c|c|c|c|}
\hline Group & DM with nephropathy & DM without nephropathy & CKD & $\mathrm{HF}$ \\
\hline Number & 15 & 61 & 27 & 7 \\
\hline \multicolumn{5}{|l|}{ Age } \\
\hline median & 55 & 59 & 53 & 63 \\
\hline interquartile range & $46-66$ & $50-69$ & $42-64$ & $46-68$ \\
\hline $\operatorname{Sex}(M / F)$ & $7 / 8$ & $35 / 26$ & $22 / 5$ & $3 / 4$ \\
\hline \multicolumn{5}{|l|}{ Pre-SCr (mg/dL) } \\
\hline median & 1.60 & 1.16 & 2.84 & 1.33 \\
\hline interquartile range & $1.21-3.20$ & $0.89-1.67$ & $1.50-4.99$ & $0.77-1.49$ \\
\hline \multicolumn{5}{|l|}{ Post-SCr (mg/dL) } \\
\hline median & 1.70 & 1.20 & 2.74 & 1.31 \\
\hline interquartile range & $1.27-3.20$ & $0.89-1.74$ & $1.42-4.58$ & $0.84-1.67$ \\
\hline$p$ value & 1.000 & 0.131 & 0.115 & 0.735 \\
\hline \multicolumn{5}{|c|}{ Pre-eGFR (mL/min/1.73 m²) } \\
\hline median & 38.68 & 55.76 & 24.00 & 54.94 \\
\hline interquartile range & $17.28-49.36$ & $35.84-72.76$ & $13.00-39.00$ & $38.68-79.36$ \\
\hline \multicolumn{5}{|c|}{ Post-eGFR (mL/min/1.73 m²) } \\
\hline median & 36.32 & 55.88 & 26.00 & 58.83 \\
\hline interquartile range & $20.00-47.00$ & $31.91-72.68$ & $15.21-47.00$ & $33.91-71.78$ \\
\hline$p$ value & 0.398 & 0.170 & 0.679 & 0.310 \\
\hline
\end{tabular}


Table 3 Changes in Serum Creatinine and eGFR of Inpatients and Outpatients

\begin{tabular}{|c|c|c|}
\hline & Inpatients & Outpatients \\
\hline Number & 149 & 11 \\
\hline \multicolumn{3}{|l|}{ Pre-SCr (mg/dL) } \\
\hline median & 1.10 & 0.84 \\
\hline interquartile range & $0.80-1.57$ & $0.80-1.00$ \\
\hline \multicolumn{3}{|l|}{ Post-SCr (mg/dL) } \\
\hline median & 1.07 & 0.81 \\
\hline interquartile range & $0.80-1.65$ & $0.70-2.08$ \\
\hline$p$-value & 0.993 & 0.656 \\
\hline \multicolumn{3}{|c|}{ Pre-eGFR $\left(\mathrm{mL} / \mathrm{min} / 1.73 \mathrm{~m}^{2}\right)$} \\
\hline median & 63.99 & 79.87 \\
\hline interquartile range & $38.52-89.00$ & $51.54-104.06$ \\
\hline \multicolumn{3}{|c|}{ Post-eGFR (mL/min/1.73 m²) } \\
\hline median & 61.28 & 82.37 \\
\hline interquartile range & $38.64-88.00$ & $32.55-101.53$ \\
\hline$p$-value & 0.673 & 0.859 \\
\hline
\end{tabular}

nature of coronary angiography may explain higher CIN rate in cardiac catheterization. In FA, fluorescein is injected intravenously in lower doses.

Another reason for lower CIN rate in FA may be the difference in the nature of contrast media used. A noniodinated fluorescein with lower molecular weight is used in FA, whereas iodinated contrast agents that have are commonly used in CT scans, cardiac angiography, and other conventional radiographic imaging techniques [29]. Although the exact mechanisms underlying contrast media nephrotoxicity are unknown, increased vasoconstrictive forces, decreased local prostaglandin- and nitric oxide-mediated vasodilatation, toxic effect of free radicals on renal tubular cells, increased intratubular pressure secondary to contrast-induced diuresis, increased urinary viscosity, and tubular obstruction are thought to play roles in the development of CIN [30]. Relatively high osmolality and viscosity of iodinated contrast media may be related to these pathogenic processes [31]. However, whether contrast media itself plays a causal role in developing acute kidney injury is controversial [20]. In a recent study, the incidence of CIN in patients undergoing contrastenhanced CT did not differ significantly from that in patients undergoing nonenhanced CT [32].
Pre-existing renal disease is one of the most important risk factor for CIN [12]. In the present study, risk stratification according to baseline $\mathrm{SCr}$ levels did not predict CIN development. Patients with co-existing diabetic nephropathy and chronic kidney disease showed no change in SCr and eGFR after FA as well. A conventional risk-stratification scheme based on SCr levels for renal function may not be an adequate method for patients undergoing FA. It raises questions as to whether FA is contraindicated in patients with elevated SCr levels or poor eGFR, and nephrology consultation before FA is an absolute necessity. In agreement with our finding, FA did not deteriorate renal function in patients with diabetic nephropathy [8]. A prospective randomized study with a large number of patients would be required to fully address that question, but the present study suggested that FA is generally safe in terms of acute renal injury, even for patients with poor kidney function.

Other risk factors for CIN include diabetes and congestive heart failure [9]. Neither diabetic patients nor those with congestive heart failure showed an increase in SCr or eGFR after FA. Advanced age has been identified as a risk factor for CIN in many studies [12, 33, 34]. We did not find the association between patient age and CIN development.

The drawbacks of this study included the small number of patients and lack of long-term prospective results. This is the first study to examine CIN associated with FA, and future larger studies are required to validate our findings. Due to the retrospective nature of the present study, the comprehensive analysis on concomitant medication, especially patients' own drugs that could have effects on renal function, could not be performed. Another limitation was that the majority of the patients included in the study were inpatients (149 of 160 patients; 93.1\%). As inpatients presumably experience a higher number of comorbid conditions relative to outpatients, the incidence of CIN in everyday clinic may actually be even lower than that found in the present study. It must be noted that FA is often performed as an outpatient clinical procedure. Both cases of CIN in the present study were found in inpatients.

\section{Conclusions}

CIN occurred in $1.3 \%$ of patients after FA. This rate was lower than reported rates after coronary angiography or

Table 4 Demographic Information, SCr Levels, and eGFR prior and Subsequent to fluorescein angiography

\begin{tabular}{lllccccc}
\hline Patient No. & Age & Sex & Pre-SCr $(\mathrm{mg} / \mathrm{dL})$ & Post-SCr $(\mathrm{mg} / \mathrm{dL})$ & Change in $\mathrm{SCr}(\mathrm{mg} / \mathrm{dL})$ & Pre-eGFR $\left(\mathrm{mL} / \mathrm{min} / 1.73 \mathrm{~m}^{2}\right)$ & Post-eGFR $\left(\mathrm{mL} / \mathrm{min}^{\prime} 1.73 \mathrm{~m}{ }^{2}\right)$ \\
\hline 1 & 53 & $\mathrm{M}$ & 0.84 & 2.08 & 1.24 & 90.0 & 34.0 \\
2 & 62 & $\mathrm{M}$ & 1.50 & 2.30 & 0.80 & 50.5 & 30.8 \\
\hline
\end{tabular}

SCr: serum creatinine

eGFR: estimated glomerular filtration rate 
contrast-enhanced CT. The use of a noniodinated agent, lower dosage, and an intravenous route of administration may account for the lower incidence of CIN associated with FA. All patients with CIN displayed normal $\mathrm{SCr}$ levels within 10 days without the need for hemodialysis, and did not show significant sequelae thereafter. $\mathrm{SCr}$ levels and eGFR remained unchanged after FA regardless of basline renal function and comorbidities. FA appeared to be generally safe in terms of acute renal injury.

\section{Abbreviations}

CIN: Contrast-induced nephropathy; CKD: Chronic kidney disease;

$\mathrm{CT}$ : Computed tomography; DM: Diabetes mellitus; DMN: Diabetic nephropathy; eGFR: Estimated glomerular filtration rate; FA: Fluorescein angiography; HF: Congestive heart failure; SCr: Serum creatinine

\section{Acknowledgements}

None.

\section{Funding}

None.

\section{Availability of data and materials}

The datasets used and/or analysed during the current study available from the corresponding author on reasonable request.

\section{Authors' contributions}

$J H L, B C$ and $C S L$ designed this study. BC, SCL, HJK, and SSK acquired the data. JHL, BC, and CSL prepared the manuscript. BC, SCL, HJK, and SSK analyzed and interpreted the data. All authors approved the final manuscript.

\section{Competing interests}

The authors declare that they have no competing interests.

\section{Consent for publication}

Not applicable.

\section{Ethics approval and consent to participate}

This study was approved by the Institutional Review Board of Severance hospital (IRB No.4-2014-0799) and was conducted in accordance with the Declaration of Helsinki. Consent to participate from the patients was waived by the Institutional Review Board of Severance hospital (IRB No.4-2014-0799) as this was a retrospective chart review study.

\section{Publisher's Note}

Springer Nature remains neutral with regard to jurisdictional claims in published maps and institutional affiliations.

\section{Author details}

${ }^{1}$ The Institute of Vision Research, Department of Ophthalmology, Yonsei University College of Medicine, Severance Hospital, Yonsei-ro 50-1 Sodaemun-gu, Seoul 03722, Republic of Korea. ${ }^{2}$ Mungyeong City Public Health Center, Mungyeong, Republic of Korea.

Received: 5 January 2017 Accepted: 12 April 2017

Published online: 19 April 2017

\section{References}

1. Levacy RA, Justice Jr J. Adverse reactions to intravenous fluorescein. Int Ophthalmol Clin. 1976;16(2):53-61.

2. Butner RW, McPherson AR. Adverse reactions in intravenous fluorescein angiography. Ann Ophthalmol. 1983;15(11):1084-6.

3. Moosbrugger KA, Sheidow TG. Evaluation of the side effects and image quality during fluorescein angiography comparing $2 \mathrm{~mL}$ and $5 \mathrm{~mL}$ sodium fluorescein. Can J Ophthalmol. 2008;43(5):571-5.

4. Pacurariu RI. Low incidence of side effects following intravenous fluorescein angiography. Ann Ophthalmol. 1982;14(1):32-6.
5. Lipson BK, Yannuzzi LA. Complications of intravenous fluorescein injections. Int Ophthalmol Clin. 1989;29(3):200-5.

6. Ho IV LVH, Lee V, Hunyor AP. Complications from fluorescein angiography: a prospective study. Clin Experiment Ophthalmol. 2009;37(8):826-7.

7. Ryan SJ. Retina. 5th ed. London: Saunders/Elsevier; 2013.

8. Kameda Y, Babazono T, Haruyama K, Iwamoto Y, Kitano S. Renal function following fluorescein angiography in diabetic patients with chronic kidney disease. Diabetes Care. 2009;32(3):e31.

9. Alemzadeh-Ansari MJ, Beladi-Mousavi SS, Feghhei M. Effect of fluorescein on renal function among diabetic patients. Nefrologia. 2011;31(5):612-3.

10. Solomon RJ, Mehran R, Natarajan MK, Doucet S, Katholi RE, Staniloae CS, Sharma SK, Labinaz M, Gelormini JL, Barrett BJ. Contrast-induced nephropathy and long-term adverse events: cause and effect? Clin J Am Soc Nephrol. 2009;4(7):1162-9.

11. Mehran R, Nikolsky E. Contrast-induced nephropathy: definition, epidemiology, and patients at risk. Kidney Int Suppl. 2006;100:S11-15.

12. Stacul F, van der Molen AJ, Reimer P, Webb JA, Thomsen HS, Morcos SK, Almen T, Aspelin P, Bellin MF, Clement O, et al. Contrast induced nephropathy: updated ESUR Contrast Media Safety Committee guidelines. Eur Radiol. 2011;21(12):2527-41.

13. Cockcroft DW, Gault MH. Prediction of creatinine clearance from serum creatinine. Nephron. 1976;16(1):31-41.

14. Levey AS, Bosch JP, Lewis JB, Greene T, Rogers N, Roth D. A more accurate method to estimate glomerular filtration rate from serum creatinine: a new prediction equation. Modification of Diet in Renal Disease Study Group. Ann Intern Med. 1999;130(6):461-70

15. National Kidney F. KJDOQI clinical practice guidelines for chronic kidney disease: evaluation, classification, and stratification. Am J Kidney Dis. 2002; 39(2 Suppl 1):S1-266.

16. Solomon R, Dumouchel W. Contrast media and nephropathy: findings from systematic analysis and Food and Drug Administration reports of adverse effects. Investig Radiol. 2006;41(8):651-60.

17. Elicker BM, Cypel YS, Weinreb JC. IV contrast administration for CT: a survey of practices for the screening and prevention of contrast nephropathy. AJR Am J Roentgenol. 2006;186(6):1651-8.

18. McCullough PA, Bertrand ME, Brinker JA, Stacul F. A meta-analysis of the renal safety of isosmolar iodixanol compared with low-osmolar contrast media. J Am Coll Cardiol. 2006:48(4):692-9.

19. Waikar SS, Bonventre JV. Creatinine kinetics and the definition of acute kidney injury. J Am Soc Nephrol. 2009;20(3):672-9.

20. Katzberg RW, Newhouse $\mathrm{JH}$. Intravenous contrast medium-induced nephrotoxicity: is the medical risk really as great as we have come to believe? Radiology. 2010;256(1):21-8.

21. Davidson C, Stacul F, McCullough PA, Tumlin J, Adam A, Lameire N, Becker CR, Panel CINCW. Contrast medium use. Am J Cardiol. 2006;98(6A):42K-58K.

22. Molitoris BA, Levin A, Warnock DG, Joannidis M, Mehta RL, Kellum JA, Ronco C, Shah S. Acute Kidney Injury N: Improving outcomes from acute kidney injury. J Am Soc Nephrol. 2007;18(7):1992-4.

23. lakovou I, Dangas G, Mehran R, Lansky AJ, Ashby DT, Fahy M, Mintz GS, Kent KM, Pichard AD, Satler LF, et al. Impact of gender on the incidence and outcome of contrast-induced nephropathy after percutaneous coronary intervention. J Invasive Cardiol. 2003;15(1):18-22.

24. Solomon R, Dauerman HL. Contrast-induced acute kidney injury. Circulation. 2010;122(23):2451-5.

25. Cramer BC, Parfrey PS, Hutchinson TA, Baran D, Melanson DM, Ethier RE, Seely JF. Renal function following infusion of radiologic contrast material. A prospective controlled study. Arch Intern Med. 1985;145(1):87-9.

26. Heller CA, Knapp J, Halliday J, O'Connell D, Heller RF. Failure to demonstrate contrast nephrotoxicity. Med J Aust. 1991;155(5):329-32.

27. Oleinik A, Romero JM, Schwab K, Lev MH, Jhawar N, Delgado Almandoz JE, Smith EE, Greenberg SM, Rosand J, Goldstein JN. CT angiography for intracerebral hemorrhage does not increase risk of acute nephropathy. Stroke. 2009;40(7):2393-7.

28. Bansal GJ, Darby M. Measurement of change in estimated glomerular filtration rate in patients with renal insufficiency after contrast-enhanced computed tomography: a case-control study. J Comput Assist Tomogr. 2009;33(3):455-9.

29. Thomsen HS. Contrast media : safety issues and esur guidelines. Berlin: Springer; 2006.

30. Gleeson TG, Bulugahapitiya S. Contrast-induced nephropathy. AJR Am J Roentgenol. 2004;183(6):1673-89. 
31. Seeliger E, Lenhard DC, Persson PB. Contrast Media Viscosity versus Osmolality in Kidney Injury: Lessons from Animal Studies. Biomed Res Int. 2014;2014:358136.

32. McDonald RJ, McDonald JS, Bida JP, Carter RE, Fleming CJ, Misra S, Williamson EE, Kallmes DF. Intravenous contrast material-induced nephropathy: causal or coincident phenomenon? Radiology. 2013;267(1):106-18.

33. Gruberg L, Mintz GS, Mehran R, Gangas G, Lansky AJ, Kent KM, Pichard AD, Satler LF, Leon MB. The prognostic implications of further renal function deterioration within $48 \mathrm{~h}$ of interventional coronary procedures in patients with pre-existent chronic renal insufficiency. J Am Coll Cardiol. 2000;36(5):1542-8.

34. Mehran R, Aymong ED, Nikolsky E, Lasic Z, lakovou I, Fahy M, Mintz GS, Lansky AJ, Moses JW, Stone GW, et al. A simple risk score for prediction of contrast-induced nephropathy after percutaneous coronary intervention: development and initial validation. J Am Coll Cardiol. 2004;44(7):1393-9.

Submit your next manuscript to BioMed Central and we will help you at every step:

- We accept pre-submission inquiries

- Our selector tool helps you to find the most relevant journal

- We provide round the clock customer support

- Convenient online submission

- Thorough peer review

- Inclusion in PubMed and all major indexing services

- Maximum visibility for your research

Submit your manuscript at www.biomedcentral.com/submit
Biomed Central 